\title{
Melt-spun polymer fibers with liquid core exhibit enhanced mechanical damping
}

Rudolf Hufenus ${ }^{\mathrm{a},{ }^{*}}$, Laura Gottardo ${ }^{\mathrm{a}}$, A. Andrés Leal ${ }^{\mathrm{a}}$, Armin Zemp ${ }^{\mathrm{b}}$, Kurt Heutschi ${ }^{\mathrm{b}}$, Philipp Schuetz $^{c, d}$, Veronika R. Meyer ${ }^{\mathrm{a}}$, Manfred Heuberger ${ }^{\mathrm{a}}$

${ }^{a}$ Laboratory for Advanced Fibers, Empa, Swiss Federal Laboratories for Materials Science and Technology, Lerchenfeldstrasse 5, CH-9014 St. Gallen, Switzerland

${ }^{b}$ Laboratory for Acoustics/Noise Control, Empa, Swiss Federal Laboratories for Materials Science and Technology, Überlandstrasse 129, CH-8600 Dübendorf, Switzerland

${ }^{c}$ Center for X-Ray Analytics, Empa, Swiss Federal Laboratories for Materials Science and Technology, Überlandstrasse 129, 8600 Dübendorf, Switzerland

${ }^{d}$ Lucerne University for Applied Science and Arts, Technikumstrasse 21, 6048 Horw, Switzerland

* Corresponding author: E-mail address: rudolf.hufenus@empa.ch, Tel: +41 587657341

E-mail addresses of all authors:

Rudolf Hufenus

Laura Gottardo

A. Andrés Leal

Armin Zemp

Kurt Heutschi

Philipp Schuetz

Veronika R. Meyer

Manfred Heuberger rudolf.hufenus@empa.ch

laura.gottardo@gmail.com

andres.leal@empa.ch

armin.zemp@empa.ch

kurt.heutschi@empa.ch

philipp.schuetz@hslu.ch

veronika.meyer@empa.ch

manfred.heuberger@empa.ch

\section{Abstract}

We demonstrate the continuous production of liquid-filled polymeric fibers in a stable meltspinning process at the pilot plant scale. Different polymers and liquids could successfully be combined over a wide range of core-sheath dimensions. The ability to produce a continuous liquid-core fiber (LCF) is attractive since post-filling of a hollow fiber with similar dimensions is not practical. We characterized the mechanical properties of the LCF's with particular attention to their damping properties. A LCF can exhibit significantly enhanced 
damping properties compared to plain polymeric filaments of same dimensions. Some possible damping mechanisms are discussed. This new type of fiber could find future applications in the enhancement of the damping factor of fiber-reinforced lightweight structures.

\section{Graphical Abstract}

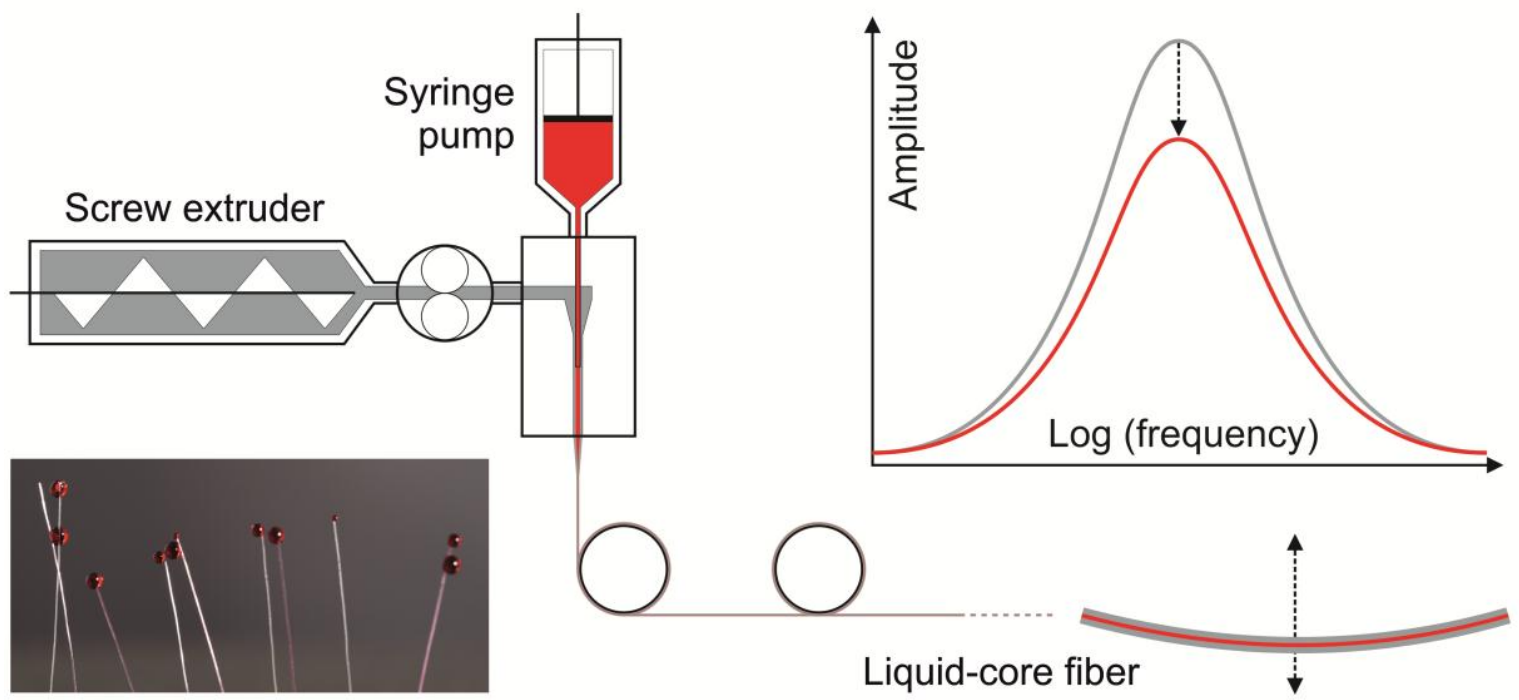

\section{Keywords}

bicomponent melt-spinning; liquid-core fiber; energy dissipation; damping factor

\section{Introduction}

In structures requiring excellent mechanical performance at very low weight, fiber-reinforced polymer composites are widely used. Here, the tensile strength is provided by continuous filaments, and the structural integrity is ensured by a polymer matrix binding the fibers together. Accompanying the high strength-to-weight ratio, lightweight composite structures are of high modulus and thus often stiff and brittle, and, as such have very poor vibration damping properties, which inherently depend on the composite's ability to dissipate mechanical energy [1]. Improvements have been achieved by using modified polymer resins [2], by adding viscoelastic fibers to the carbon fiber tows [3], or by using surface-modified 
carbon fibers [4]. The drawbacks of said improvements are diminished mechanical properties and the need for modified polymer resins and filaments which are not commercially available. Regarding vibrational damping, studies in different fields of science have shown that a quasiincompressible fluid can enhance the damping characteristics in a stiff system. For instance, analyses of fluid-filled cylindrical shells have shown that the presence of a liquid enhances linear damping, which lowers the linear natural frequencies of vibration [5]. Zhang et al. have compared the response of a cylindrical shell with and without water, showing that for most frequencies under analysis $(0-90 \mathrm{~Hz})$, the liquid-filled shell exhibits a lower displacement amplitude than the empty shell [6]. A favorable way to integrate a liquid in a lightweight composite structure would be in a fiber form, as a fiber can precisely and seamlessly be blended into a composite material, without compromising its structural integrity.

Considering the range of possibilities offered by bicomponent fibers - the two components usually being synthetic polymers - their overall mechanical performance is ultimately limited by the polymer properties [7, 8]. For instance, in the case of a core-sheath arrangement, the core polymer may provide the desired mechanical characteristics, whereas the sheath polymer adds other specific functionality $[9,10]$. However, a growing number of reports in the literature refer to the use of hollow fibers and membranes to incorporate solid-liquid mechanics as a new element, so for example in micro-extraction [11], molecular sieving [12] or vascular networks in multifunctional materials [13]. Hollow fibers are a closely related type of core-sheath fibers in which the core is composed of gaseous fluid (e.g. air). They can be produced by wet, dry or melt spinning $[14,15]$, and they have specialized uses in medical devices [16], but the largest volume market is in thermal insulation products [17].

Melt-spinning is the fastest and most economical of all fiber-making processes; whereby hollow fibers can be produced using two different types of spinneret geometries. In a "segmented arc spinneret", the polymer melt flows through three or more separated arc slits, and subsequently fuses together below the spinneret to form a tubular shape [18-20]. In a 
"tube in orifice spinneret", the polymer melt is spun through an annular opening, while inside the annulus a "lumen fluid", usually nitrogen or $\mathrm{CO}_{2}$, is injected through a coaxial conduit $[21,22]$.

As the fiber length increases and the diameter decreases, it becomes increasingly more difficult to post-fill a hollow fiber with a liquid [23, 24]. The Hagen-Poiseuille law [25] predicts that a hollow fiber of $30 \mu \mathrm{m}$ core diameter and just $1000 \mathrm{~m}$ length would take more than 3 years for post-filling with water at $3 \cdot 10^{5} \mathrm{~Pa}$. The development of a liquid-core fiber (LCF) in a single processing step is thus a very elegant alternative. Recently, a very interesting and novel approach in the development of monofilament hollow fibers has been established in the area of microfluidic spinning [26-28]. Microfluidic spinning however is still far from the technological maturity level already available with melt-spinning.

Therefore, we envisioned the development of a continuous filament, filled with a liquid during fiber melt-spinning, which would enable cost-effective high-speed production of such a material. Among the common spinnerets used for melt-spinning, only the concentric "pipein-pipe mixer" could be adapted to a process which combines polymer and liquid, while other designs like "plate mixers" cannot guarantee sufficient sealing for a pressurized liquid [29]. Therefore, not only a specific spinneret, but an entire spin pack had to be designed to enable the co-extrusion of a molten polymer and a liquid in a continuous and stable process.

The multi-component spinning process combining liquid and polymer is prone to known instabilities. The typical melt instability that affects the flow of a polymer melt in a capillary is melt fracture: entangled polymer melts extruded through a spin pack at high shear rates often exhibit a wavy or spiral distortion of the extrudate [30-32]. The occurrence of this instability is relevant here and depends on many factors including polymer chemistry, architecture, molecular weight and distribution, and polymer-wall surface interactions [33, 34]. Typical wall shear stress values are in the range of $3 \cdot 10^{4}$ to $9.75 \cdot 10^{4} \mathrm{~Pa}$ [35]. 
Another unwanted spinning instability is the so-called draw resonance [36, 37], which is a finite-amplitude periodic fluctuation of the cross-section area at the fiber take-up position [30]. Here, the inherent elasticity of a filament during spinning produces undulations that begin at a critical drawdown ratio (ratio between take-up speed and extrusion velocity at the exit of the spin pack) [31, 38]. Draw resonance occurs at constant take-up speed when small fluctuations in the fiber cross-section area produce oscillations in the fiber tension that amplify the fluctuations [39]. For example, polypropylene (PP) is particularly susceptible to draw resonance when quenched in a water bath [38]; usually draw resonance does not occur with polymers like PP, PET or PA when air-quenched [40]. The critical drawdown ratio is known to be affected by polymer properties, extrusion temperature, filament nominal diameter, and distance between spinneret and water bath [41].

In a preliminary model study, we showed how the systematic analysis of the co-flowing behavior of two liquids with different rheological properties, coupled with computational fluid dynamics studies of two-phase systems of Newtonian and viscoelastic fluids, led to the design of a customized extrusion spin pack with the possibility to obtain a biphasic fluid oscillator [42]. The simplified version of this injection geometry is adopted here to enable the co-extrusion of a common polymer melt with a selected liquid of interest. The fibers produced are characterized with respect to their morphology and mechanical properties, with special attention toward their capability to absorb mechanical energy upon bending or under vibration.

\section{Materials and Methods}

\subsection{Polymers and liquids}

Extrusion trials were performed using several types of polymers in combination with a selection of different liquids. The choice of the liquid in combination with the elevated 
processing temperatures is recognized as the most restraining factor. Therefore, a suitable liquid has to meet several elementary requirements:

i) It must exhibit a relatively low vapor pressure, e.g. $<10^{5} \mathrm{~Pa}$, at the processing temperature to prevent exit spraying,

ii) the thermal stability of the liquid should be high enough,

iii) the liquid has to be non-corrosive to the extrusion equipment,

iv) the liquid must not act as solvent for the polymer component.

Two grades of polydimethylsiloxane (PDMS), PMX200-300cSt (no. 101) and PMX2002000cSt (no. 102), were purchased from Dow Corning (DGE, Credimex AG, Sarnen Switzerland). Breox 75 W 2050 (no. 103), a polyalkylene glycol (PAG), was supplied by BASF (BASF SE, Ludwigshafen, Germany). Table 1 summarizes the specifications of the liquids used in this work.

\section{Table 1}

Liquids used with properties as specified by the providers. Vapor pressure at $200^{\circ} \mathrm{C}$ has been measured in-house with an autoclave (Model IV, Carl Roth GmbH, Karlsruhe, Germany).

\begin{tabular}{|c|c|c|c|c|c|c|}
\hline $\begin{array}{c}\text { Liquid } \\
\text { no. }\end{array}$ & Label & $\begin{array}{c}\text { Kinematic } \\
\text { viscosity }[\mathrm{cSt}]\end{array}$ & $\begin{array}{c}\text { Surface tension } \\
{[\mathrm{N} / \mathrm{m}]}\end{array}$ & $\begin{array}{c}\text { Density } \\
{\left[\mathrm{kg} / \mathrm{m}^{3}\right]}\end{array}$ & Flash point & $\begin{array}{c}\text { Vapor pressure } \\
{[\mathrm{kPa}] \text { at } 200^{\circ} \mathrm{C}}\end{array}$ \\
\hline 101 & $\begin{array}{c}\text { PMX200- } \\
300 \mathrm{cSt}\end{array}$ & 300 & $0.021\left(25^{\circ} \mathrm{C}\right)$ & 968 & $>326^{\circ} \mathrm{C}$ & $15 \pm 5$ \\
102 & $\begin{array}{c}\mathrm{PMX200-} \\
2000 \mathrm{cSt} \\
\mathrm{Breox} \mathrm{75} \mathrm{W} \\
2050\end{array}$ & 2000 & $0.021\left(25^{\circ} \mathrm{C}\right)$ & 970 & $>326^{\circ} \mathrm{C}$ & $10 \pm 5$ \\
103 & $2025\left(40^{\circ} \mathrm{C}\right)$ & not specified & 1097 & $252^{\circ} \mathrm{C}$ & $20 \pm 5$ \\
\hline
\end{tabular}

Along the same lines, the polymer should have a relatively low processing temperature to match the liquid thermal stability, and it should exhibit a high melt-strength to allow fiber formation from the melt even in the presence of a certain excess of core pressure.

Therefore, we selected five different polymer types from different suppliers: Two random ethylene-propylene copolymer grades, PP 621P (polymer no. 201) and PCR25 (polymer no. 
202), and a low-density polyethylene, LDPE 1965 T (polymer no. 203), were provided by Sabic (Sabic Europe, Sittard, The Netherlands). EMS-Grivory (EMS-Chemie AG, Domat/Ems, Switzerland) supplied two grades of polyamide, the Grilamid L 16, which is a polyamide 12 (polymer no. 204), as well as Grilon F34 (polymer no. 205), a polyamide 6 variant. Table 2 lists these polymers together with their specifications (the flexural modulus is reported according to ASTM D 790).

\section{Table 2}

Polymers used. Properties specified by provider. MFR = melt flow index (ISO 1133).

\begin{tabular}{|c|c|c|c|c|c|c|}
\hline $\begin{array}{c}\text { Polymer } \\
\text { no. }\end{array}$ & Label & MFR [g/10min] & $\mathrm{T}_{\mathrm{m}}(\mathrm{DSC})$ & $\begin{array}{l}\text { Density } \\
{\left[\mathrm{kg} / \mathrm{m}^{3}\right]}\end{array}$ & $\begin{array}{c}\text { Flexural } \\
\text { modulus }[\mathrm{MPa}]\end{array}$ & Provider \\
\hline 201 & PP 621P & $8\left(230^{\circ} \mathrm{C} / 2.16 \mathrm{~kg}\right)$ & $145^{\circ} \mathrm{C}$ & 905 & 850 & Sabic \\
\hline 202 & PCR 25 (PP) & $25\left(230^{\circ} \mathrm{C} / 2.16 \mathrm{~kg}\right)$ & $140^{\circ} \mathrm{C}$ & 905 & 1150 & Sabic \\
\hline 203 & LDPE 1965T & $65\left(190^{\circ} \mathrm{C} / 2.16 \mathrm{~kg}\right)$ & $104^{\circ} \mathrm{C}$ & 919 & not specified & Sabic \\
\hline 204 & $\begin{array}{l}\text { Grilamid L } 16 \\
\text { (PA 12) }\end{array}$ & not specified & $178^{\circ} \mathrm{C}$ & 1010 & not specified & $\begin{array}{l}\text { EMS- } \\
\text { Chemie }\end{array}$ \\
\hline 205 & $\begin{array}{l}\text { Grilon F } 34 \\
\text { (PA 6) }\end{array}$ & not specified & $222^{\circ} \mathrm{C}$ & 1140 & not specified & $\begin{array}{l}\text { EMS- } \\
\text { Chemie }\end{array}$ \\
\hline
\end{tabular}

\subsection{Processing equipment}

For the spinning of fluid-core fibers, a customized pilot line has been assembled in our laboratory. The central equipment consisted of a twin screw extruder (Thermo Haake Rheomex OS) equipped with a gear metering pump (Haake melt pump OS) to control the polymer volumetric flow rate in the range of $30-40 \mathrm{~cm}^{3} / \mathrm{min}$ (Fig. 1). A high-pressure syringe pump (Telegyne ISCO 260D purchased from SCF processing LTD, Drogheda, Ireland) was used to inject the liquid into the co-extrusion spin pack with volumetric flow rates in the nominal range of $1-15 \mathrm{~cm}^{3} / \mathrm{min}$. 


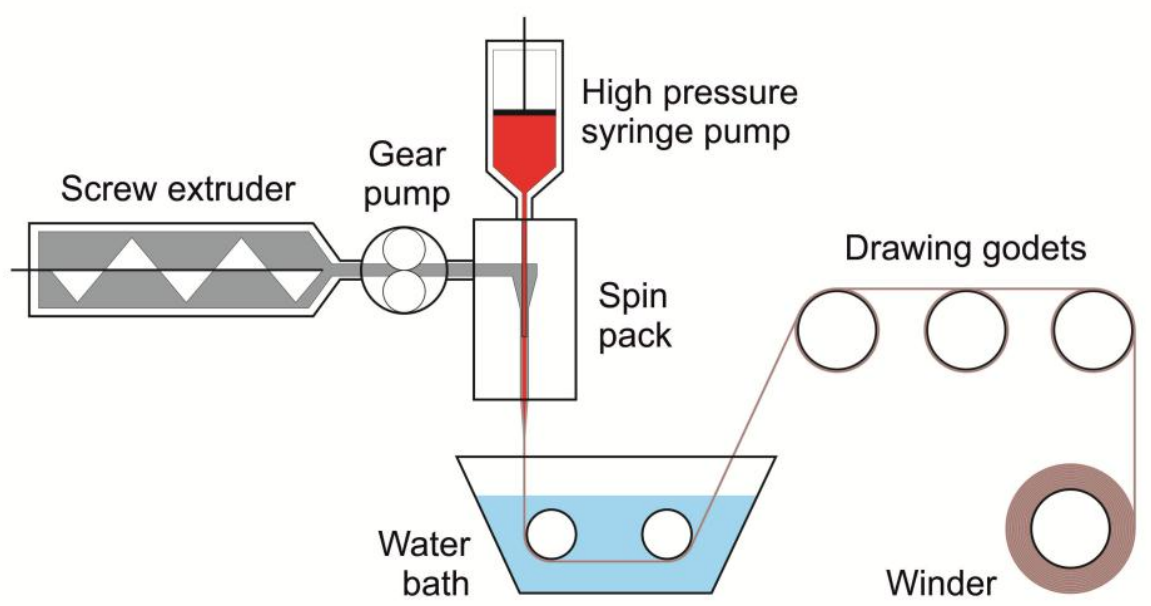

Fig. 1. Scheme of the co-extrusion equipment. Diameters of godets and winder spool were $100 \mathrm{~mm}$. Spinneret to water bath distance varied between 100 and $500 \mathrm{~mm}$. Dimensions of spin pack see Fig. 2. By way of illustration, the colorless liquid is represented in red.

Polymer melt and liquid were combined in a newly-developed co-extrusion spin pack, which is further described in section 2.3 below. The bicomponent extrudate exiting the spin pack was cooled in a water bath (room temperature) and post-drawn using a drawing unit composed of three heated godets $(100 \mathrm{~mm}$ diameter). Finally, the fiber was collected onto spools (100 mm diameter) using a customized winder (SSM, Horgen, Switzerland). Take-up velocities were varied between 20 and $70 \mathrm{~m} / \mathrm{min}$, and the draw ratio, namely the ratio between the winder speed and that of the take-up godet, was varied in the range $1-6$.

\subsection{The co-extrusion spin pack}

As nonlinear flow properties of polymer melts [43], caused by the energy stored in the viscoelastic melt under pressure [44, 45], would lead to flow instabilities in co-extrusion of a molten polymer and a liquid core [42], a special spin pack is needed that enables the meltspinning of a LCF in a continuous and stable process. Fig. 2 shows a 3D cross section of the customized spin pack. The polymer is supplied from the gear pump through the inlet on the left hand side; it flows into a conical chamber before entering an annular co-flow channel with diameter of $\mathrm{OD}_{\mathrm{F}}=4 \mathrm{~mm}$. The inner injection capillary conveys the core liquid $\left(\mathrm{OD}_{\mathrm{C}}=3 \mathrm{~mm}\right.$, $\left.\mathrm{ID}_{\mathrm{C}}=2.4 \mathrm{~mm}\right)$. The polymer can partially expand downstream, at the expense of the 
pressurized liquid at the capillary outlet. A flow channel (length-to-diameter ratio $\mathrm{L} / \mathrm{D}=10$ ) allows for controlled relaxation in a co-flow region before exiting the spin pack. A constant temperature is maintained by using an appropriate heating bracket which encases the entire co-extrusion spin pack.

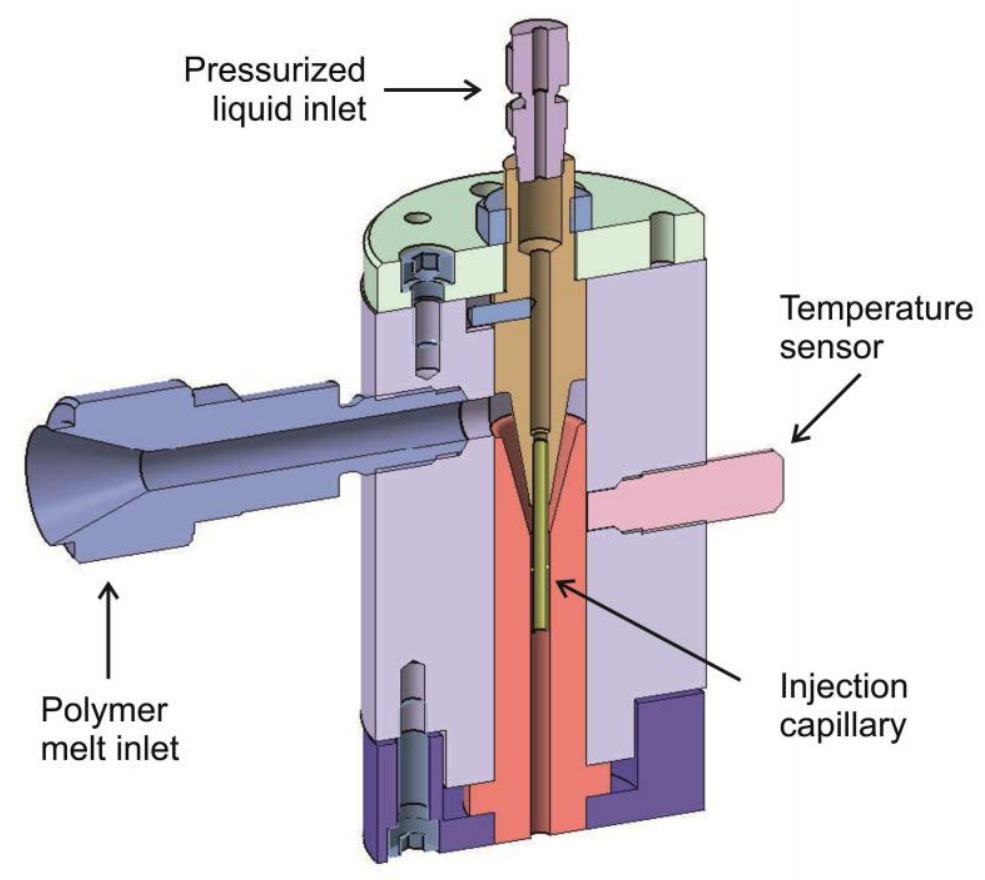

Fig. 2. Cross section of the liquid/polymer co-extrusion spin pack with concentric co-flow region. Inner diameter of the co-flow channel $\mathrm{OD}_{\mathrm{F}}=4 \mathrm{~mm}$, outer diameter of the injection capillary $\mathrm{OD}_{\mathrm{C}}=3 \mathrm{~mm}$, inner diameter $\mathrm{ID}_{\mathrm{C}}=2.4 \mathrm{~mm}$. Distance between capillary outlet and spinneret exit: $40 \mathrm{~mm}$ (length-to-diameter ratio $\mathrm{L} / \mathrm{D}=10$ ).

The design of the co-extrusion spin pack provides a readily interchangeable geometry since it is built modularly. Namely, it is possible to change the injection capillary or the co-flow channel by replacing the respective parts. This design is the result of previous model experiments and numerical simulations using different injection geometries [42]; the goal here is to enable non-oscillating stable processing conditions for a maximally wide range of processing parameters. Therefore, all fibers discussed in this paper were produced with a simple capillary injection.

The spin pack design provides a well-sealed inner channel and delivers a nearly symmetrical flow of the polymer melt at the circular exit. Stagnant areas are prevented by limiting the 
volume of the conical chamber as far as possible. The flow rate of the liquid is kept constant in the process and the pressure exerted by the syringe pump, which can be varied up to a maximum of $50 \mathrm{MPa}$, prevents the polymer backflow through the liquid-filled capillary. The flow channel with $\mathrm{L} / \mathrm{D}=10$ is longer than usual in fiber melt-spinning ( $\mathrm{L} / \mathrm{D} \sim 4$ ), so that the co-flow can reach quasi steady state before the exit.

\subsection{Fiber characterization}

The micro morphology of the extrudate was analyzed using optical microscopy on cross sections and lateral portions of the fiber. To further characterize the fiber core morphology, computer tomography $(\mathrm{CT})$ measurements were performed on a micro-CT consisting of an Xray tube XT9160-TXD (Viscom Technology, Hannover, Germany) with $\mu \mathrm{m}$-sized focal spot operated at an acceleration voltage of $80 \mathrm{kV}$ and a current of $120 \mu \mathrm{A}$; the sample was mounted on a rotation table UPR-160F air (Micos, Dübendorf, Switzerland), and the projection images were recorded on a flat panel detector 1621-CN3 ES (Perkin Elmer, Walluf, Germany). The tomographic cross-sections were reconstructed with an in-house GPU implementation of the Feldkamp-David-Kress algorithm [FDK] [46]. A total of 720 projections were recorded to reconstruct a volume of $1500 \times 1500 \times 1500$ voxels with a physical size of $13.68 \mu \mathrm{m}$ in each direction.

The visualization of the fiber thicknesses was performed using VG Studio Max 2.2 (Volume Graphics, Heidelberg, Germany) based on the wall-thickness module.

The fiber samples were embedded into an epoxy matrix to assure the maximum mechanical stability upon scanning and to avoid fiber overlap. Polymer and liquid could be readily distinguished thanks to their different X-ray absorbance. In each slice, the individual components were discriminated by a threshold method, followed by pixel area counting.

To assess the mechanical energy dissipation characteristics of fluid-core fibers we used two different methods. Firstly, a two-point bending test [47] was used to measure the energy 
dissipated by the fiber during slow cycles of bending and relaxation (Fig. 3); a $50 \mathrm{~mm}$ segment of a fiber is positioned manually within the test device, which consisted of two parallel clamping jaws with a fixative recess on each side. The gap width, $G$, is changed in reciprocating manner; the starting gap between the supports was $\mathrm{G}_{1}=15 \mathrm{~mm}$ and the final gap was $\mathrm{G}_{2}=10 \mathrm{~mm}$. One clamping jaw was thus displaced with controlled velocities of $\mathrm{v}_{1}=0.05$ $\mathrm{mm} / \mathrm{s}, \mathrm{v}_{2}=0.5 \mathrm{~mm} / \mathrm{s}$ and $\mathrm{v}_{3}=5 \mathrm{~mm} / \mathrm{s}$, equivalent to reciprocating cycle frequencies of $\mathrm{f}_{1}=0.005$ $\mathrm{Hz}, \mathrm{f}_{2}=0.05 \mathrm{~Hz}$ and $\mathrm{f}_{3}=0.5 \mathrm{~Hz}$, respectively. Forces were measured during both phases of loading and unloading using a load cell of appropriate resolution attached to the clamping jaw at rest.

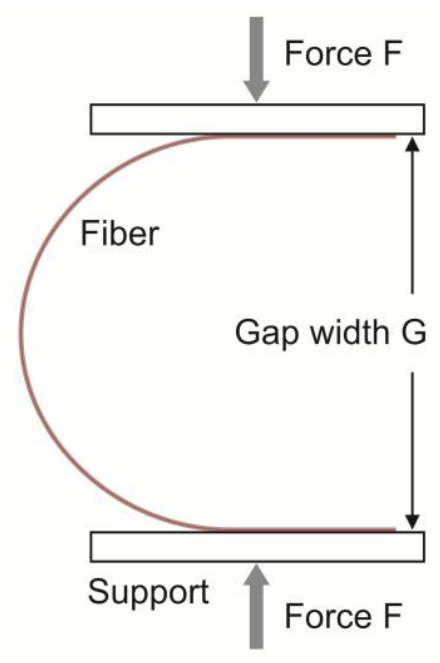

Fig. 3. Schematic of the two-point bending device measuring a fiber (length $50 \mathrm{~mm}$ ): $\mathrm{G}=$ gap between clamps $(10-15 \mathrm{~mm}), \mathrm{F}=$ force applied/measured.

For the second type of measurement, a flexural vibration device was built to measure the dynamic damping factor of a fiber near its resonance frequency (Fig. 4a). A $100 \mathrm{~mm}$ long fiber segment was tensioned with a suspended loading weight of $100 \mathrm{~g}$. This loading mechanism allowed constant loading, compensating for possible small fiber creep. The other extremity was fixed to a piezoelectric actuator/translator where a frequency sweep from $50 \mathrm{~Hz}$ to $1500 \mathrm{~Hz}$ was applied. The velocity amplitude of the fiber at constant piezo amplitude was measured using a laser vibrometer Polytech PDV 100 (Polytech, Waldbronn, Germany), 
which allows to determine the surface velocity of vibrating objects contact-free, based on the Doppler shift.
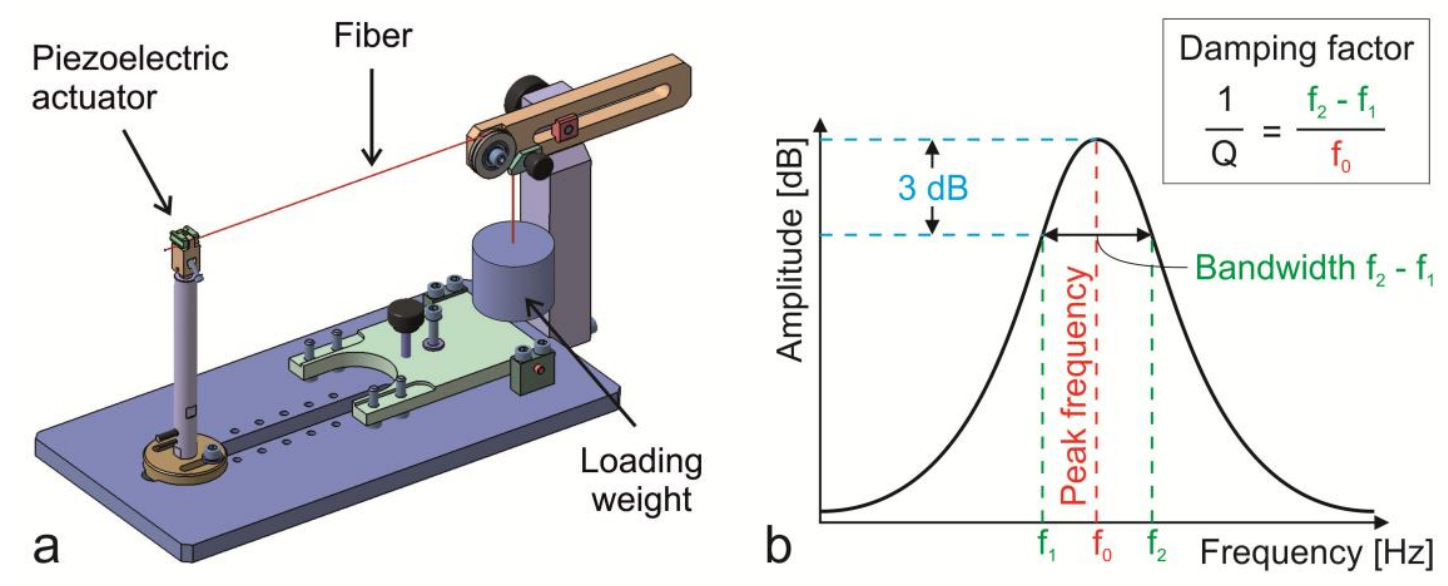

Fig. 4. a) Scheme of the flexural vibrating device. Length of free fiber segment: $100 \mathrm{~mm}$. Loading weight: $100 \mathrm{~g}$. b) Scheme of amplitude vs. frequency of an excited fiber at resonance. $\mathrm{f}_{0}=$ peak (center) frequency, $\mathrm{f}_{1}, \mathrm{f}_{2}=$ frequencies with amplitude at $-3 \mathrm{~dB}$ of peak value, $\mathrm{Q}=$ quality factor [48].

The damping factor was calculated from the bandwidth of resonance, i.e. the range of frequency where the amplitude was at $-3 \mathrm{~dB}$ of its peak value $\left(\mathrm{f}_{2}-\mathrm{f}_{1}\right)$ at the resonance frequency $\mathrm{f}_{0}$ (cf. Fig. $4 \mathrm{~b}$ ). This excitation frequency range was sufficient to cover the first three modes of resonance.

A hot blade was used to melt-cut the fiber into well-defined segments with sealed ends, in order to prevent any liquid loss. The fibers were carefully checked to confirm the good sealing of their ends before as well as after the damping measurements.

\section{Results and discussion}

\subsection{Fiber making}

In the course of this work numerous extrusion trials were performed. A selection of process conditions for some particularly relevant samples is listed in Table 3. 


\section{Table 3}

Selection of relevant processing parameters, including type of polymer and liquid used, flow rates of the respective pumps, take-up velocities, and draw ratios. For polymer and liquid nomenclature be referred to Table 1 and Table 2, respectively.

\begin{tabular}{|c|c|c|c|c|c|c|}
\hline \multirow[b]{2}{*}{ Fiber no. } & \multicolumn{2}{|c|}{ Fiber sheath } & \multicolumn{2}{|c|}{ Fiber core } & \multirow{2}{*}{$\begin{array}{l}\text { Take-up } \\
\text { velocity } \\
{[\mathrm{m} / \mathrm{min}]}\end{array}$} & \multirow[b]{2}{*}{ Draw ratio } \\
\hline & Polymer no. & $\begin{array}{l}\text { Flow rate } \\
{\left[\mathrm{cm}^{3} / \mathrm{min}\right]}\end{array}$ & Liquid no. & $\begin{array}{l}\text { Flow rate } \\
{\left[\mathrm{cm}^{3} / \mathrm{min}\right]}\end{array}$ & & \\
\hline 301 & 201 & 40 & - & - & 50 & 1 \\
\hline 302 & 201 & 30 & 101 & 10 & 50 & 1 \\
\hline 303 & 201 & 40 & - & - & 50 & 6 \\
\hline 304 & 201 & 30 & 101 & 10 & 50 & 6 \\
\hline 305 & 202 & 30 & 102 & 10 & 50 & 1 \\
\hline 306 & 202 & 30 & 102 & 10 & 50 & 6 \\
\hline 307 & 202 & 40 & - & - & 50 & 1 \\
\hline 308 & 202 & 30 & 103 & 10 & 50 & 1 \\
\hline 309 & 202 & 40 & - & - & 50 & 6 \\
\hline 310 & 202 & 30 & 103 & 10 & 50 & 6 \\
\hline 311 & 204 & 30 & 103 & 5 & 50 & 4 \\
\hline 312 & 205 & 30 & 101 & 5 & 100 & 3.7 \\
\hline
\end{tabular}

The first extrusion trials were performed using polymer no. 201 (PP) and liquid no. 101 (PDMS 300cSt). Here, the initial scope was to investigate various process parameters, such as stability, maximum amount of liquid that can be co-extruded, and maximum draw ratio achievable. The best results were obtained with a polymer flow at a gear pump rate of nominally $30 \mathrm{~cm}^{3} / \mathrm{min}$. We achieved stable conditions down to the lowest flow rates with the liquid no. 101, while the maximum flow rate possible in combination with the polymer no. 201 was limited to about $15 \mathrm{~cm}^{3} / \mathrm{min}$. At a higher rate of liquid injection the extrudate at the spin pack first started to oscillate and finally brake-up.

Due to the large viscosity difference between polymer melt and liquid, a migration of the liquid core (lower viscosity) toward the pipe wall is expected due to an annular flow instability [49-52]. The resulting cross-sectional redistribution gradually evolves with flow distance (e.g. flowing time) and thus requires a high L/D ratio $[53,54]$ to develop fully. An initial small core eccentricity is inevitable due to small spin pack asymmetries. The eccentricity is then amplified by the above-described annular flow instability. As soon as the core is sufficiently off-center, the asymmetric momentum distribution can also result in a critical buckling of the fiber at the exit of the spin pack [54, 55]. The buckling will gain 
significance with increasing difference in flow velocity (i.e. momentum). If, in addition, the liquid volumetric flow rate is increased at constant melt flow rate, this may cause serious thinning of the polymer sheath and provoke leakage or fatal rupture of the extrudate at the exit. These effects are practically limiting the maximum core to sheath ratio.

The extruded fibers were quenched in a water bath that was kept at room temperature (approx. $20{ }^{\circ} \mathrm{C}$ ). The fibers were then continuously drawn using up to three godets at successively higher speed, as shown in Fig. 1. The take-up velocity of the first godet was set fixed in an adjustable range between 20 and $70 \mathrm{~m} / \mathrm{min}$, and then the speed of the intermediate godets and the winder were adjusted to define the overall draw ratio. The maximum overall draw ratio hence achieved was 6; a further increase of the draw ratio resulted in break-up of the extrudate at the godet where the elongation limit was reached. This elongation limit is not related to the maximum molecular alignment in the polymer, but it is due to a draw-necking instability generated in the filament, occurring at any slightly thinner fiber segment; such small diameter variations are commonly produced by small draw resonances $[37,56]$. Based on the results achieved with these first extrusion trials, we then focused on the production of PP fibers with $25 \%$ volume of liquid core, which corresponds to a $10 \mathrm{~cm}^{3} / \mathrm{min}$ nominal flow rate of the liquid at a gear pump rate of $30 \mathrm{~cm}^{3} / \mathrm{min}$. In Table 3 , the respective processing parameters and material combinations are listed (viz. fibers no. 301-310). The drawing conditions included a fixed take-up velocity of $50 \mathrm{~m} / \mathrm{min}$ at the first (and in this case only) godet, which resulted in a draw ratio of 6 . Fibers with draw ratio one (winding speed equal to take-up velocity) were also produced as reference, in order to assess the effect of the draw ratio on morphology and mechanical response. Due to the excellent flow properties of the polypropylene used for these trials (polymer no. 202, namely with good melt strength and MFR $=25 \mathrm{~g} / 10 \mathrm{~min}$ at $230^{\circ} \mathrm{C} / 2.16 \mathrm{~kg}$ ), it was possible to combine this polymer sheath with a variety of different core fluids. 
The selected liquids revealed kinematic viscosities over a wide range, from 60 to $2025 \mathrm{cSt}$ at $40{ }^{\circ} \mathrm{C}$. From the processing point of view, the influence of the liquid's viscosity was negligible. Interestingly, the following characterization will show that a different viscosity of the core liquid has a significant influence on the damping properties of the fibers at room temperature.

Other important characteristics of the liquid are thermal stability and chemical inertness at processing temperatures $\left(195-200^{\circ} \mathrm{C}\right.$ for polymers no. 201 and $202,220^{\circ} \mathrm{C}$ for polymer no. 204, and $275^{\circ} \mathrm{C}$ for polymer no. 205). To ensure a stable process, liquids must neither decompose nor release any type of gases upon processing. Therefore, the liquids were selected to possess a high flash point and a low vapor pressure $\left(<10^{5} \mathrm{~Pa}\right.$ at processing temperature). Preliminary experiments showed that the best candidates for extrusion trials, due to their superior thermal properties compared to other liquids, were the two grades of PDMS (PMX200-300cSt, liquid no. 101; PMX200-2000cSt, liquid no. 102) and the polyalkylene glycol (Breox 75 W 2050, liquid no. 103).

Polyolefins like polypropylene are known to have a good processability due to the molecularlevel flexibility of their aliphatic polymer chains, and the processing temperature is comparatively low. We also tested additional polymers, i.e. polyamides, in order to check the feasibility to process materials with superior mechanical properties to the final fiber. In Table 3, respective processing parameters and material combinations are listed (viz. fibers no. 311 and 312). With PA12 (polymer no. 204), it was possible to extrude a fiber with a maximum liquid content of $14 \%$. Here, three godets with successively increasing rotation speed were utilized to realize an overall draw ratio $\mathrm{DR}=4$, with take-up velocities of $50 \mathrm{~m} / \mathrm{min}, 100$ $\mathrm{m} / \mathrm{min}$ and $200 \mathrm{~m} / \mathrm{min}$, respectively. On the other hand, when extruding PA6 (polymer no. 205), the maximum achieved draw ratio was 3.7; a minimal take up velocity of $100 \mathrm{~m} / \mathrm{min}$ at the first godet was necessary due to the melt rheology of PA6. 
A practical assessment of the melt flow behavior of polypropylene can be gained from determination of the melt flow index (MFR, ISO 1133). The pseudo-plastic nature of PP strongly depends on the molecular weight distribution $[57,58]$. The polymer used is a random ethylene-propylene copolymer, which lowers the crystallinity and the melting point, compared to standard PP grades. Regarding polyamides, the principal structural element participating in intermolecular interactions is the amide moiety, which constitutes an energetic barrier to chain rotation. Consequently, the melting point and flow behavior are related to the concentration of amide groups or the number of $\mathrm{CH}_{2}$ units interlinking these groups [59]. In comparison to PA6, a reduction in melting temperature is characteristic for PA12 [60], which allows to reduce the processing temperature.

A plain polymeric fiber was extruded as reference fiber besides each LCF, using the same processing parameters (extrusion temperature profile, take-up velocity and draw ratio). These plain reference fibers were also spun with the same co-extrusion spin-pack, but having the liquid inlet inoperative; instead a slightly higher polymer flow rate of $40 \mathrm{~cm}^{3} / \mathrm{min}$ was used, to obtain the same total volumetric flow rate and fiber diameter.

\subsection{Morphology of the fibers}

Depending on the flow rates of polymer and liquid, and the take-up velocity, the diameters of the prepared fibers were approximately $1 \mathrm{~mm}$ for undrawn fibers $(\mathrm{DR}=1)$, and between 0.35 and $0.47 \mathrm{~mm}$ for drawn fibers. The geometrical assessment of fabricated fluid core fibers by means of optical microscopy is difficult due to low contrast. Therefore, the morphology of the extrudates was examined using X-ray computer tomography (CT). Micro CT is capable of generating 3D models, which provide structural metric information about the fiber core. Examples of 3D images of fibers 302 and 304 are shown in Fig. 5. Due to differences in the material density, it is possible to distinguish the outer polymeric mantle (gray) from the fluid core (red). The analysis of a representative number of fibers reveals that the liquid core is 
indeed continuously connected along the fiber; the core is typically eccentric with respect to the fiber center.

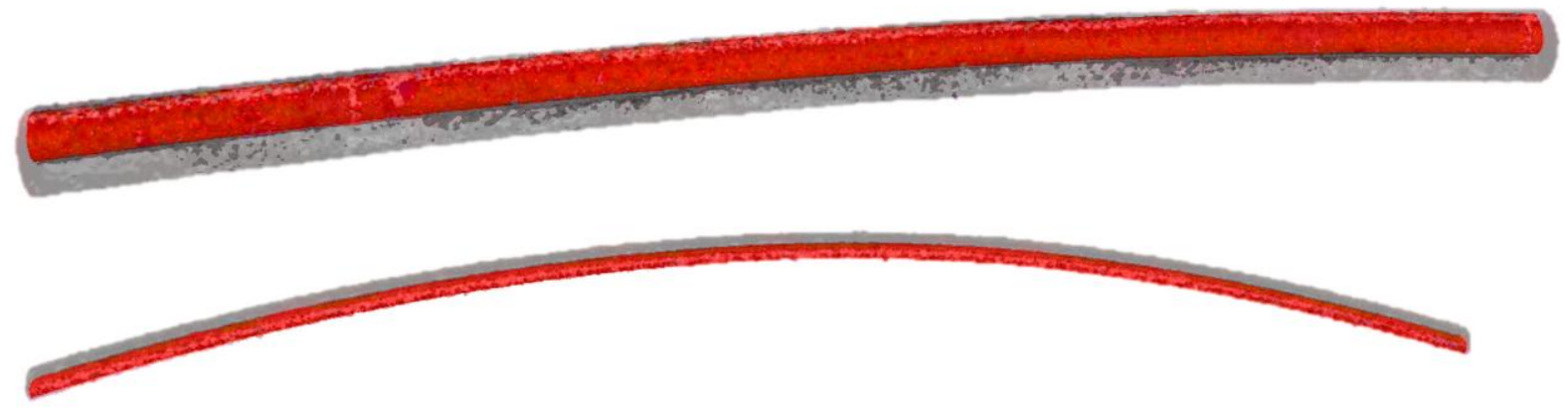

Fig. 5. 3D perspective reconstruction of $C T$ data obtained with fluid core fibers: top: draw ratio, $\mathrm{DR}=1$ (no. 302, thick) and bottom: $\mathrm{DR}=6$ (no. 304, thin). The polymer phase is colored gray while the liquid core is represented in red (the liquid is colorless). The dark spots result from the noise of the measurements and the subsequent reconstruction.

The 3D visualizations (Fig. 5) are generated from the combination of single CT crosssectional scans which are stored as an image stack. It is possible to extract the total area of the fiber and the relative amount of polymer and liquid within each cross section. Here, fibers 302 and 304 were analyzed over a length of $20 \mathrm{~mm}$. The total area of the cross section of the two fibers is $\mathrm{A}_{302}=(6.67 \pm 0.17) \cdot 10^{5} \mu \mathrm{m}^{2}$ and $\mathrm{A}_{304}=(1.18 \pm 0.07) \cdot 10^{5} \mu \mathrm{m}^{2}$, respectively. We note that the area ratio $\mathrm{A}_{302} / \mathrm{A}_{304}$ is equal to 5.65, which is in good agreement with the nominal draw ratio $\mathrm{DR}=6$ applied upon processing. From these areas the fiber diameters can be calculated as $920 \mu \mathrm{m}$ and $390 \mu \mathrm{m}$, respectively.

For both fibers, the measured volumetric core to sheath (liquid to polymer) ratio determined by $\mathrm{CT}$ is equal to 0.43 , with a standard deviation of 0.02 . During processing, the core to sheath ratio was nominally set to 0.33 (cf. Table 3 ). In the CT reconstruction, the core is overestimated and the sheath is truncated due to the high level of noise, which required very low values for the threshold separating epoxy and sheath, as well as overly high cutoffs separating sheath and core. The results show that the co-extrusion was stable upon processing with a constant throughput of both phases. 
In all the analyzed fibers, independent of the amount of liquid used and of the draw ratio, we found that the liquid core is eccentric. An initial core eccentricity caused by the spin pack can be amplified by the aforementioned annular flow instability. However, since the residence time of polymer and liquid inside the spinning head is short, this instability evolution is not complete [61] and the core remains inside the polymer phase.

If the fibers were produced with a significantly reduced liquid flow rate of $0.8 \mathrm{~cm}^{3} / \mathrm{min}$ and a polymer flow rate of $4 \mathrm{~cm}^{3} / \mathrm{min}$, the core was not completely filled with liquid, but with isolated droplets (Fig. 6). The prevailing mechanism for droplet formation in this case is the Rayleigh-Plateau instability [42]. From the micro CT images, it can be seen that the dimensions of droplets and their distribution along the fiber axis are somewhat irregular. Filling liquids at reduced rate represents an elegant means to produce continuous fibers with individual encapsulated liquid droplets. Additional extrusion trials will be needed to find optimized processing parameters for more regular and more densely packed liquid droplet encapsulation. So far, we could observe that the processing window to obtain a fiber with droplets is very narrow and difficult to reproduce. A possible dynamic approach to address this problem with modified injection geometry has recently been described elsewhere [42].

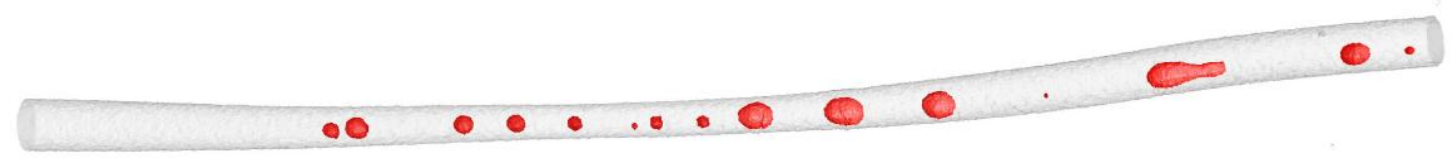

Fig. 6. 3D reconstruction of a polymeric fiber with isolated liquid droplets in the inner core. The fiber was co-extruded from polymer no. 203 (nominal flow rate $4 \mathrm{~cm}^{3} / \mathrm{min}$ ) and liquid no. 101 (nominal flow rate $0.8 \mathrm{~cm}^{3} / \mathrm{min}$ ). The polymer phase is in light grey while the droplets are red. Their volumes are between 0.005 and $0.04 \mu \mathrm{m}^{3}$.

\subsection{Slow-rate bending dissipation}

The energy dissipated upon repeated bending cycles of LCFs and their plain fiber references was measured using the two-point bending technique illustrated in Fig. 3. The hysteresis of a force-displacement curve (i.e. difference of area under the curves in Fig. 7) is a measure for the amount of energy a fiber dissipates upon one bending cycle. Since the bending cycles are 
performed via repeated clamping jaw motion, the change of hysteresis with progressive cycle number bears additional information about irreversible inelastic deformations.

Fig. 7a shows the bending forces of the first cycle measured with LCFs 302 and 304, and their corresponding plain fiber references (301 and 303), performed with the jaw velocity $v=5$ $\mathrm{mm} / \mathrm{s}$. Analysis of these loading curves reveals that the converted energy (area under the curve) upon bending of a fiber with $\mathrm{DR}=1$ is roughly one order of magnitude higher than the energy necessary to bend a fiber of the same material with $\mathrm{DR}=6$. The same is true for LCFs 308 and 309, and their corresponding references 307 and 309 (data not shown). Two possible effects may contribute to this phenomenon in combination: First, a larger fiber diameter $(\mathrm{DR}=1)$ will lead to higher bending stresses, as described by the Euler-Bernoulli bending theory. Both, tensile and compressive stresses throughout the cross section of the filament are directly proportional to the distance from the stress-free line (neutral axis), reaching a maximum at the surface of the fiber [62]. Second, tensile stresses at the outer bending radius may be high enough to locally induce inelastic cold-drawing in the undrawn $\mathrm{DR}=1$ fiber.

If the thicker liquid-core fibers are directly compared to their plain fiber reference, namely LCF $302(\mathrm{DR}=1)$, compared to its respective plain fiber reference $301(\mathrm{DR}=1)$, we observe lower bending energy for the LCF. This again underlines the importance of the local colddrawing contribution to the energy dissipation of the plain fiber during the first bending cycle. This same trend is seen over all tested fibers and clamping jaw velocities between 0.05 and $0.5 \mathrm{~mm} / \mathrm{s}$ (data not shown). This finding may be explained by the fact that a liquid-core fiber may reduce the maximum bending stresses and thus reduce local cold-drawing effects by a change of the cross section (flattening).

A different picture arises when comparing the normalized energy dissipation of the thinner fiber types at higher DR=6, namely LCF sample no. 304, and its respective plain fiber reference 303 of $\mathrm{DR}=6$; now, the bending energy of the first cycle is higher for the LCF than for the plain polymer fiber reference (true for all fibers and velocities, data not shown). We 
expect that at $\mathrm{DR}=6$ the effect of local cold-drawing is no longer a predominant energy dissipation mechanism due to the already highly aligned molecules causing more elastic material response. The higher energy dissipation in the $\mathrm{DR}=6$ liquid-core fiber is interesting and shall be scrutinized further below at higher frequencies. We think the origin of this effect is linked to the ability of the liquid core to couple local stresses to distant regions of the fiber via enhanced pressure propagation.
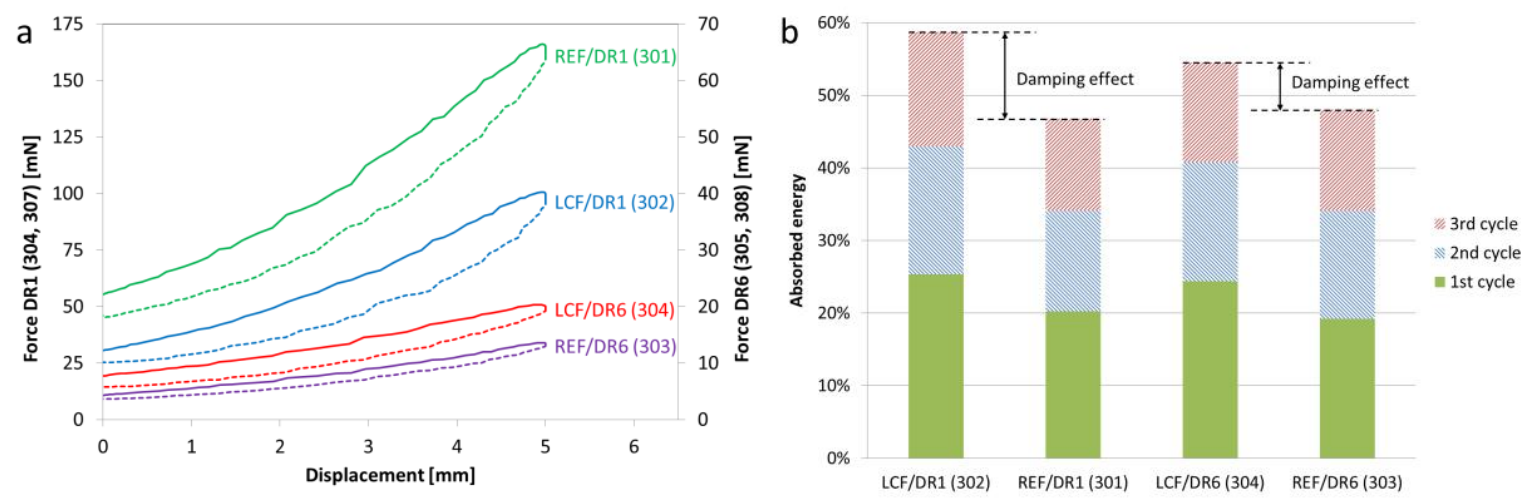

Fig. 7. Bending cycles performed with a clamping jaw speed of $5 \mathrm{~mm} / \mathrm{s}$ (total travel distance of $5 \mathrm{~mm}$ ) for fibers spun from polymer 201 (PP with flexural modulus $\mathrm{E}_{201}=850 \mathrm{MPa}$ ) with liquid 101 (PDMS with kinematic viscosity $\mu_{101}=300 \mathrm{cSt}$ ). We show the liquid-filled fibers (LCF) 302, 304, and their respective pure polymer references (REF) 301, 303. a) Force versus displacement of the first bending cycle, where the underlying area corresponds to the amount of energy conversion. Data of the undrawn fibers $(\mathrm{DR}=1)$ refer to the left $y$-axis and data of the drawn fibers $(D R=6)$ refer to the right $y$-axis. Loading branches are depicted as continuous lines, unloading branches as dotted lines. b) Absorbed energy over the first three bending cycles. The absorbed energy is calculated based on the hysteresis (c.f. hysteresis area in Fig. 7a) expressed in percent of the total energy needed for a first bending. This representation allows more direct comparison between liquid-core fibers and their plain fiber references.

To study the evolution of energy dissipation, Fig. 7b shows the amount of energy absorbed in three successive bending-relaxation cycles for all the analyzed fibers as determined from their hysteresis curves. Here, for the purpose of more direct comparison, we introduce the residual absorbed energy in percent of the overall energy dissipated during the first loading cycle. This absorbed energy (in \%) is calculated from the hysteresis energy (in $\mu \mathrm{J}$ ) of each cycle in relation to the bending energy (in $\mu \mathrm{J}$ ) of the first loading branch (cf. Fig. 7a). With this normalization we eliminate the influence of the different fiber cross-sections on bending stresses. The cycle sum results show that fibers with a liquid core (no. 302 and 304) absorb 
more energy than their plain references (also true for LCF 308 and 310, data not shown). This is a promising tendency in terms of possible applications of liquid-filled fibers for mechanical damping.

The dynamical mechanism underlying energy dissipation seems to be a combination of rheological dissipation of the liquid, and, the combination of core pressure propagation with the viscoelastic response of the polymer sheath at a distance. These mechanisms also affect the dynamic response at higher frequencies, as we shall see.

\subsection{Dynamic damping}

To assess the dynamic damping properties, we have excited different fibers at higher frequencies according to the method shown in Fig. 4. The measured damping factors for the first three modes of oscillation are displayed in Fig. 8. Each measurement was repeated at least three times, while the constant tensile stress was secured by a loading weight to ensure constant tension regardless of small strains due to polymer creep. Two liquid-core fibers of draw ratio $\mathrm{DR}=6$ are shown in Fig. 8 with their respective plain fiber references. We note that the lower viscosity liquid-core fiber no. 304 exhibits a significantly higher damping factor than any of the other fibers. This result is in agreement with the quasi-static assessment discussed above, and also reproducible with results obtained in a similar experiment where the fibers are end-clamped and excited with a loudspeaker (data not shown).

We note that the higher viscosity liquid-core fiber no. 306 with the slightly stiffer polymer sheath does not show a significant increase of damping factor versus the plain reference. The presence of a liquid core alone is not sufficient to obtain enhanced damping. The effect seems to depend on a correct tuning of material properties and therefore has potential for further optimization. 


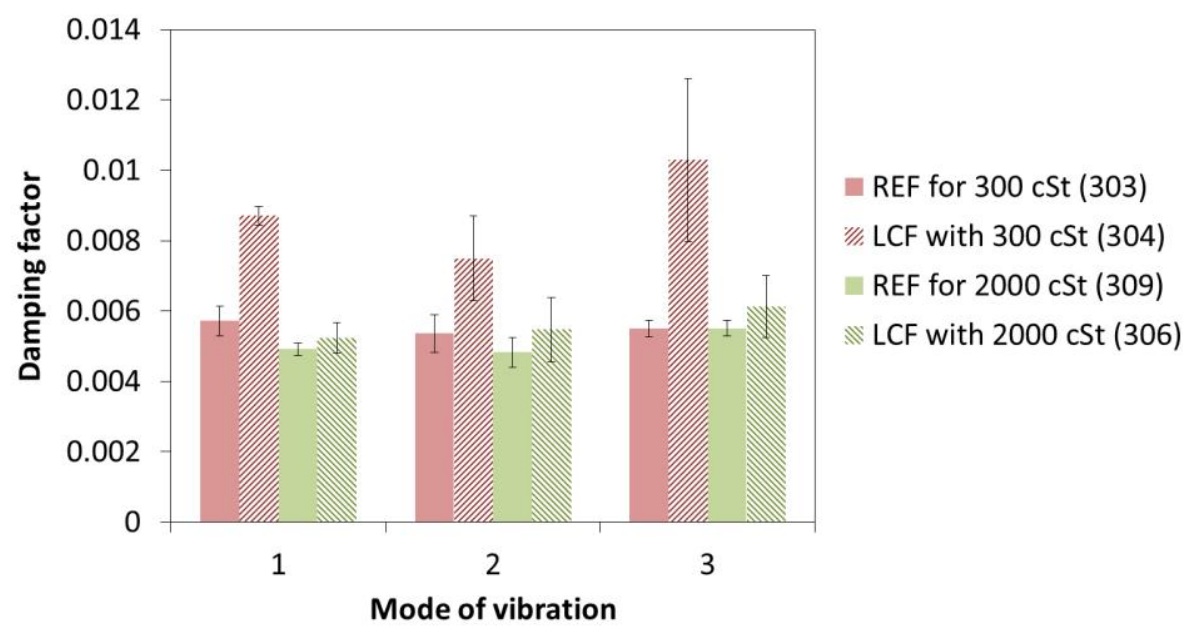

Fig. 8. Damping factors of the first three modes of vibrations of fiber 304 (filled with PDMS $300 \mathrm{cST}$, no. 101) and its reference 303 (pure PP, no. 201), and fiber 306 (filled with PDMS $2000 \mathrm{cSt}$, no. 102) and its reference 309 (pure PP, no. 202). The draw ratio of all fibers is $\mathrm{DR}=6$. The mode frequencies are: $\mathrm{f}_{1} \approx 300 \mathrm{~Hz}, \mathrm{f}_{2} \approx 600 \mathrm{~Hz}, \mathrm{f}_{3} \approx 900 \mathrm{~Hz}$.

A more detailed discussion of the liquid-core damping effect requires identification of the dissipation mechanism. The attenuation of acoustic waves was studied for the analogue of a liquid core inside a polymeric pipe. There the attenuation effect is known to be enhanced by a low polymer wall modulus and high loss tangent [63]. Further experiments will be needed to understand the damping effect in liquid-core fibers. The enhanced pressure propagation phenomenon suggested by the low-frequency experiments can help distribute the energy over larger portions of the fiber. It seems thus reasonable that delocalized dissipation due to energy transport through the core should be considered as the starting hypothesis.

\section{Conclusions}

We demonstrated the feasibility of spinning liquid-core fibers in a continuous process using an adapted bicomponent melt-spinning approach. The validated processing window includes a range of different liquid-polymer combinations, provided that the vapor pressure of the liquid remains below $10^{5} \mathrm{~Pa}$ at the processing temperature. 
Optical and micro CT characterization of the liquid-core fibers reveals a typical eccentric core location that results from a known co-flow instability. A reduced liquid flow in the coextrusion process can be exploited to generate isolated encapsulated liquid depots.

The continuous liquid-core fiber can exhibit enhanced energy dissipation properties. Low frequency bending tests suggest that pressure propagation along the incompressible fluid core combines with damping properties of the polymer sheath at a distance. Significant increases of the damping factor observed at higher frequencies suggest that this effect can be further optimized with suitable liquid/polymer combinations.

We think that this work sets the stage for a new type of fiber damping element that can be readily integrated into fiber-based materials like composites or textiles.

\section{Acknowledgements}

Part of this study was kindly supported by the Swiss National Science Foundation's Smart Materials Program (NRP-62). The authors thank Pierluigi Barbadoro and Benno Wuest for extrusion and fiber melt-spinning, Milijana Jovic, Khalifah Salmeia and Olivia Neururer for vapor pressure measurements, as well as Eduardo Mazza and Arabella Mauri (both ETH Zurich, Department of Mechanical and Process Engineering) for introduction and access to the two point bending test device. 


\section{References}

1. Gibson RF, Chen Y, and Zhao H. Improvement of vibration damping capacity and fracture toughness in composite laminates by the use of polymeric interleaves. Journal of Engineering Materials and Technology-Transactions of the Asme 2001;123(3):309314.

2. Bascom WD, Gweon SY, and Grande D. MULTIPHASE MATRIX POLYMERS FOR CARBON-FIBER COMPOSITES. Advances in Chemistry Series 1993(233):519-537.

3. Martone A, Giordano M, Antonucci V, and Zarrelli M. Enhancing damping features of advanced polymer composites by micromechanical hybridization. Composites Part aApplied Science and Manufacturing 2011;42(11):1663-1672.

4. Tehrani M, Safdari M, Boroujeni AY, Razavi Z, Case SW, Dahmen K, Garmestani H, and Al-Haik MS. Hybrid carbon fiber/carbon nanotube composites for structural damping applications. Nanotechnology 2013;24(15).

5. Pellicano F and Amabili M. Stability and vibration of empty and fluid-filled circular cylindrical shells under static and periodic axial loads. International Journal of Solids and Structures 2003;40(13-14):3229-3251.

6. Zhang Y, Zhang Z-y, Tong Z-p, and Hua H-x. Finite element modeling of a fluid filled cylindrical shell with active constrained layer damping. Journal of Shanghai Jiaotong University (English Edition) 2005;E-10(4):449-455.

7. Houis S, Schreiber F, and Gries T. Bicomponent fibers (Part 2). Chemical Fibers International 2008;58(3):158-165.

8. Perret E, Reifler FA, Hufenus R, Bunk O, and Heuberger M. Modified crystallization in PET/PPS bicomponent fibers revealed by small-angle and wide-angle X-ray scattering. Macromolecules 2013;46(2):440-448.

9. Hufenus R, Affolter C, Camenzind M, and Reifler FA. Design and Characterization of a Bicomponent Melt-Spun Fiber Optimized for Artificial Turf Applications. Macromolecular Materials and Engineering 2013;298(6):653-663.

10. Hufenus R, Reifler FA, Maniura-Weber K, Spierings A, and Zinn M. Biodegradable Bicomponent Fibers from Renewable Sources: Melt-Spinning of Poly(lactic acid) and Poly[(3-hydroxybutyrate)-co-(3-hydroxyvalerate)]. Macromolecular Materials and Engineering 2012;297(1):75-84.

11. Chao YY, Jian ZX, Tu YM, Wang HW, and Huang YL. An on-line push/pull perfusionbased hollow-fiber liquid-phase microextraction system for high-performance liquid chromatographic determination of alkylphenols in water samples. Analyst 2013;138(11):3271-3279.

12. Brown AJ, Brunelli NA, Eum K, Rashidi F, Johnson JR, Koros WJ, Jones CW, and Nair S. Interfacial microfluidic processing of metal-organic framework hollow fiber membranes. Science 2014;345(6192):72-75.

13. Williams HR, Trask RS, Weaver PM, and Bond IP. Minimum mass vascular networks in multifunctional materials. Journal of the Royal Society Interface 2008;5(18):55-65.

14. Hills WH. Apparatus for making profiled multi-component yarns. Patent US5344297A. 1994. pp. 25.

15. Broaddus CR. Batts and articles of new polyester fiberfill. Patent US5104725A. 1992. pp. 10.

16. Sonnenschein MF. Hollow fiber microfiltration membranes from poly(ether ether ketone) (PEEK). Journal of Applied Polymer Science 1999;72(2):175-181.

17. Jaffe $M$ and East AJ. Polyester Fibers. In: Lewin M, editor. Handbook of Fiber Chemistry: CRC Press 2007. pp. 1-29.

18. Oh TH, Lee MS, Kim SY, and Shim HJ. Studies on melt-spinning process of hollow fibers. Journal of Applied Polymer Science 1998;68(8):1209-1217. 
19. Takarada W, Ito H, Kikutani T, and Okui N. Studies on high-speed melt spinning of noncircular cross-section fibers. I. Structural analysis of As-spun fibers. Journal of Applied Polymer Science 2001;80(9):1575-1581.

20. Rwei SP. Formation of hollow fibers in the melt-spinning process. Journal of Applied Polymer Science 2001;82(12):2896-2902.

21. Huang Q, Seibig B, and Paul D. Polycarbonate hollow fiber membranes by melt extrusion. Journal of Membrane Science 1999;161(1-2):287-291.

22. De Rovère A and Shambaugh RL. Melt-spun hollow fibers: Modeling and experiments. Polymer Engineering \& Science 2001;41(7):1206-1219.

23. Leal AA, Naeimirad M, Gottardo L, Schuetz P, Zadhoush A, and Hufenus R. Microfluidic behavior in melt-spun hollow and liquid core fibers. International Journal of Polymeric Materials 2016;65(9):451-456.

24. Naeimirad M, Zadhoush A, Abrishamkar A, Pishevar A, and Leal AA. Melt-spun liquid core fibers: physical and morphological characteristics. Iranian Polymer Journal 2016;DOI 10.1007/s13726-016-0431-y.

25. Kirby B. Micro- and Nanoscale Fluid Mechanics: Transport in Microfluidic Devices: Cambridge University Press, 2010.

26. Choi CH, Yi H, Hwang S, Weitz DA, and Lee CS. Microfluidic fabrication of complexshaped microfibers by liquid template-aided multiphase microflow. Lab on a Chip 2011;11(8):1477-1483.

27. Cheng Y, Zheng FY, Lu J, Shang LR, Xie ZY, Zhao YJ, Chen YP, and Gu ZZ. Bioinspired Multicompartmental Microfibers from Microfluidics. Advanced Materials 2014;26(30):5184-5190.

28. Jun Y, Kang E, Chae S, and Lee SH. Microfluidic spinning of micro- and nano-scale fibers for tissue engineering. Lab on a Chip 2014;14(13):2145-2160.

29. Fitzgerald WE and Knudsen JP. Mixed-Stream Spinning of Bicomponent Fibers1. Textile Research Journal 1967;37(6):447-453.

30. Hatzikiriakos SG and Migler KB. Overview of Processing Instabilities. In: Hatzikiriakos SG and Migler KB, editors. Polymer Processing Instabilities. New York: Marcel Dekker, 2005. pp. 1-12.

31. Denn MM. Fifty years of non-Newtonian fluid dynamics. AIChE Journal 2004;50(10):2335-2345.

32. Baird DG and Collias DI. Polymer processing: Principles and design: John Wiley \& Sons, 1998.

33. Denn MM. Extrusion instabilities and wall slip. Annual Review of Fluid Mechanics, vol. 33, 2001. pp. 265-287.

34. Migler KB, Son Y, Qiao F, and Flynn K. Extensional deformation, cohesive failure, and boundary conditions during sharkskin melt fracture. Journal of Rheology 2002;46(2):383-400.

35. Vinogradov GV, Friedman ML, Yarlykov BV, and Malkin AY. Unsteady flow of polymer melts: Polypropylene. Rheologica Acta 1970;9(3):323-329.

36. Petrie CJS and Denn MM. Instabilities in polymer processing. AIChE Journal 1976;22(2):209-236.

37. Jung HW and Hyun JC. Fiber spinning and film blowing instabilities. In: Hatzikiriakos SG and Migler KB, editors. Polymer processing instabilities: Control and understanding, vol. 102: Marcel Dekker Series, 2004. pp. 321-382.

38. Yoo HJ. Draw resonance in polypropylene melt spinning. Polymer Engineering \& Science 1987;27(3):192-201.

39. Larson RG. Instabilities in viscoelastic flows. Rheologica Acta 1992;31(3):213-263.

40. Kase S. Studies on melt spinning. IV. On the stability of melt spinning. Journal of Applied Polymer Science 1974;18(11):3279-3304. 
41. Mei-Fang Z and Yang HH. Polypropylene Fibers. Handbook of Fiber Chemistry, Third Edition, vol. Volume 8: CRC Press, 2006.

42. Heuberger M, Gottardo L, Dressler M, and Hufenus R. Biphasic fluid oscillator with coaxial injection and upstream mass and momentum transfer. Microfluidics and Nanofluidics 2015;19(3):653-663.

43. Eggers $\mathbf{J}$ and Villermaux E. Physics of liquid jets. Reports on Progress in Physics 2008;71(3).

44. Hatzikiriakos SG and Migler KB. Polymer Processing Instabilities: Control and Understanding. New York: Marcel Dekker, 2005.

45. Agassant JF, Arda DR, Combeaud C, Merten A, Münstedt H, Mackley MR, Robert L, and Vergnes B. Polymer processing extrusion instabilities and methods for their elimination or minimisation. International Polymer Processing 2006;21(3):239-255.

46. Feldkamp LA, Davis LC, and Kress JW. Practical cone-beam algorithm. Journal of the Optical Society of America A 1984;1(6):612-619.

47. Schifferle A, Neels A, Papes O, Dommann A, and Mazza E. Combined testing for MEMS characterization. Procedia Engineering 2010;5(0):878-881.

48. Valtorta D, Lefèvre J, and Mazza E. A new method for measuring damping in flexural vibration of thin fibers. Experimental Mechanics 2005;45(5):433-439.

49. Karami A and Balke ST. Polymer blend de-mixing and morphology development of immiscible polymer blends during tube flow. Polymer Engineering and Science 2000;40(11):2342-2355.

50. Lee BL and White JL. Notes: Experimental Studies of Disperse Two-Phase Flow of Molten Polymers Through Dies. Journal of Rheology 1975;19(3):481-492.

51. Utracki LA, Dumoulin MM, and Toma P. Melt rheology of high density polyethylene/polyamide-6 blends. Polymer Engineering \& Science 1986;26(1):34-44.

52. Lohfink GW and Kamal MR. Morphology and permeability in extruded polypropylene/ethylene vinyl-alcohol copolymer blends. Polymer Engineering and Science 1993;33(21):1404-1420.

53. Dooley J. Coextrusion Instabilities. In: Hatzikiriakos SG and Migler KB, editors. Polymer Processing Instabilities. New York: Marcel Dekker, 2005. pp. 383-426.

54. Karagiannis A, Hrymak AN, Vlachopoulos J, and Vlcek J. Coextrusion of polymer melts. In: Covas JA, Agassant JF, Diogo AC, Vlachopoulos J, and Walters K, editors. Rheological fundamentals of polymer processing: Kluwer Academic Publishers, 1995. pp. 113-137.

55. Yu J-P. Producing Bicomponent Fibers: Spinneret Design is Crucial. International Fiber Journal 1998;13:49-53.

56. Tadmor $\mathrm{Z}$ and Gogos CG. Principles of Polymer Processing, 2 ed.: John Wiley \& Sons, 2006

57. Dealy JM and Wang J. Melt Rheology and its Applications in the Plastics Industry, 2nd ed.: Springer, 2013.

58. Muke S, Ivanov I, Kao N, and Bhattacharya SN. The melt extensibility of polypropylene. Polymer International 2001;50(5):515-523.

59. Yang HH. Polyamide Fibers. Handbook of Fiber Chemistry, Third Edition, vol. Volume 8: CRC Press, 2006.

60. Palmer RJ. Polyamides, Plastics. Encyclopedia of Polymer Science and Technology: John Wiley \& Sons, Inc., 2002.

61. Yue P, Zhou C, Dooley J, and Feng JJ. Elastic encapsulation in bicomponent stratified flow of viscoelastic fluids. Journal of Rheology (1978-present) 2008;52(4):1027-1042.

62. Leal AA, Deitzel JM, and Gillespie JW. Compressive Strength Analysis for High Performance Fibers with Different Modulus in Tension and Compression. Journal of Composite Materials 2009;43(6):661-674. 
63. Horne MP and Hansen RJ. Sound propagation in a pipe containing a liquid of comparable acoustic impedance. Journal of the Acoustical Society of America 1982;71(6):1400-1405. 